\title{
VIZ: The visualization assessment and training Web site
}

\author{
DAWN G. BLASKO, KATHRYN HOLLIDAY-DARR, DEREK MACE, and HOLLY BLASKO-DRABIK \\ Penn State Erie, Behrend College, Erie, Pennsylvania
}

\begin{abstract}
The VIZ Website (http://viz.bd.psu.edu/viz/) was developed as a free and open portal for assessment and training of spatial skills. Using Macromedia Authorware, it allows the collection of response times and accuracies from four spatial tasks: mental rotation, paper folding, water level judgments, and spatial working memory. Additional tasks are under development. The site has been used for a variety of teaching and research purposes. For example, incoming engineering students have completed the tasks to assess their spatial skills before beginning their graphics courses. Those with poorer skills can then receive the appropriate remedial instruction. The VIZ site has also been used to teach about spatial cognition and to do research outside the laboratory setting. Finally, we are using the site to conduct basic research on spatial cognition, including an examination of the factors that may reduce gender differences in performance.
\end{abstract}

Several years ago, the faculty for the engineering program at Penn State Erie was concerned about the low grades and high dropout rates of 1st-year students. The faculty felt that many students, despite their high grades in high school, appeared to lack basic spatial skills and that women might be at a particular disadvantage. Blasko and Holliday-Darr (1999) tested incoming engineering students on a number of potential variables that might influence retention and success in 1st-year engineering courses, including educational background, motivation for college, parental influence, and verbal and spatial skills, and found that the strongest predictors of 1st-year GPA and retention were math SAT scores and scores on tests of basic spatial abilities, such as mental rotation. Importantly, although the two were sometimes correlated, the spatial tasks predicted variance over and above those on the SAT alone. This led to the development of VIZ: The Visualization Assessment and Training Website (http://viz.bd.psu.edu/viz/). The aim was to develop an open portal for testing and training spatial skills and the subsequent dissemination of that research (HollidayDarr, Blasko, \& Dwyer, 2000).

\section{Overview of VIZ}

The VIZ site was based on the collaborative model of Psych Experiments on the Web: http://psychexps.olemiss. edu. Like the psych experiments team, we chose to use

Financial support was provided by a Penn State Faculty Initiative Technology grant. We also thank Carol Dwyer and Carla Torgerson for their support in instructional design and Gretta Meyers for her initial programming support. Our thanks also go out to the many students that have been involved in the VIZ project, including student coordinators Jessica Turos and Amy Johnson. Students were supported by the Penn State Erie Undergraduate Research Fellowship program. Correspondence concerning this article should be addressed to D. G. Blasko, H\&SS Penn State Erie, 5091 Station Road Erie, PA 16563 (e-mail: dawnblasko@psu.edu).
Macromedia Authorware modules that would allow us to collect response times and accuracies for analysis while also providing immediate feedback to users (McGraw, Tew, \& Williams, 2000).

In the first phase of the project, the VIZ team focused on creating Web-based modules to assess three areas of spatial ability that, according to meta-analysis, are statistically separable: mental rotation, spatial visualization, and spatial perception (Voyer, Voyer, \& Bryden, 1995). The degree of gender difference has been shown to differ depending on the task. The site includes three widely used measures of spatial cognition. (1) The water-level test (Piaget \& Inhelder, 1956) is used to measure spatial perception, often defined as the ability to determine spatial relationships among objects despite distracting information. (2) The paper-folding task is similar to the Differential Aptitude Tests: Space Relations (DAT:SR; Bennett, Seashore, \& Wesman, 1973) and measures spatial visualization. Spatial visualization was defined by Voyer et al. (1995) as the ability to manipulate complex spatial information when several stages are needed to produce the correct solution. (3) The mental rotation task (MRT; Shepard \& Metzler, 1971) is used to assess the ability to mentally manipulate three-dimensional objects in order to imagine them in a different perspective or orientation. Of the three tasks, mental rotation has shown the largest gender difference favoring males, followed by spatial perception and then spatial visualization, which shows small or nonsignificant gender differences (Voyer et al., 1995). We also began testing a fourth task, spatial working memory, which measures the ability to remember and manipulate spatial information (Shah \& Miyake, 1996). Spatial working memory is a key cognitive resource that is potentially used in all spatial tasks.

Information from the VIZ Website is collected using Authorware on the person's own computer and is then sent to an Access database on our server. Each user is 
presented with feedback at the end of each task. A person using the VIZ site is assigned a confidential ID, and the database recognizes any previous user and assigns the same ID. This is useful for prepost comparisons. Classes or groups can be set up on the site so that data can be easily separated.

\section{Correspondence of Web-Based and Laboratory Tests}

We now have data from over 1,500 participants who took at least one of the tasks. The results replicate the basic findings in the literature, and this provides further support for other claims (McGraw et al., 2000) that valid and reliable data can be collected using on-line methodologies. Although timing and control are not always as good in Webbased tasks as they are in a carefully controlled laboratory setting, this limitation may be offset by the greater accessibility and convenience of Web-based tasks.

An analysis of the data that we have so far is similar to what has been reported in laboratory studies. We examined data from 335 participants who completed all three tasks for the first time. Consistent with the claims of Voyer et al. (1995), the three spatial tasks are not highly correlated. The only significant correlation was between the MRT and the water-level task $[r(334)=.24, p<$ $.001]$. The MRT did not correlate with the folding task $(r=-.08)$. Similarly, the water-level task did not correlate with the folding task $(r=-.05)$. This suggests that an accurate description of an individual's spatial skill requires the measurement of multiple spatial tasks.

When we analyzed the data by task and gender, we saw the expected overall advantage for men over women (see Figure 1). For the paper-folding task $(N=334)$, women were slightly less accurate than men [69\% to $65 \%$; $t(331)=2.01, p=.03]$. On the water-level task, the gen- der difference was more robust, with women correct on $57 \%$ of trials versus men's $71 \%[t(494)=5.40, p<.001]$. The MRT showed the expected speed advantage for same trials over different trials $(p<.0001)$, and there were clear gender differences, with $83 \%$ correct for males and $75 \%$ correct for females $[t(444)=5.96, p<.0001]$. These data match the results of laboratory tasks described by Kimura (1999), where sex differences favoring males on the MRT are typically more robust than sex differences in spatial visualization tasks such as the paper-folding task.

\section{Applications of VIZ}

The site has now been used for three rather different purposes. First, we have used it to assess the incoming spatial skills of our engineering majors and to identify those who might benefit from additional help. This research is the first step in extending this testing and remediation to majors in other disciplines that require spatial skills, such as architecture, landscape design, and mathematics (Devlin, 2001). Second, VIZ has been used to train students in cognitive psychology and research methods. As a research tool, the site allows for distributed data collection and is flexible enough to accommodate a variety of experimental manipulations. Finally, we have used the site to begin a number of research projects designed to validate the use of the Internet as a data collection tool and to identify spatial strategies that might serve to reduce or eliminate gender differences (Wraga, Creem, \& Proffitt, 2000). In the sections below, we will briefly illustrate a sample of the findings from each of these areas.

Spatial skills assessment. One of our first goals was to provide an assessment of spatial skills for engineering students. All incoming mechanical and plastics engineering technology (MET and PLET) students take a required graphics course in their first semester. These stu-

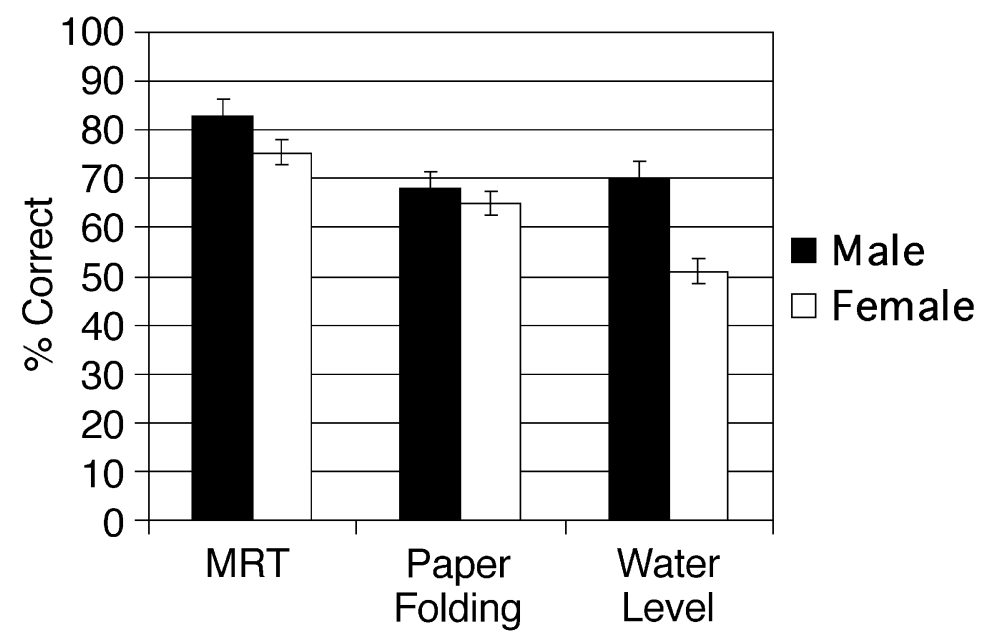

Figure 1. Mean percentage correct for men and women for the three spatial tasks on the VIZ Website: the mental rotation task (MRT), the paper-folding task, and the water-level task. Error bars show standard error of the mean. In all three tasks, men outperformed women, although the difference was smallest in the paper-folding task. 
dents were pretested using the VIZ Website. Those who scored at the 60th percentile or lower were directed to supplemental instruction sessions, where they did paperbased, hands-on, and computer-based exercises in an attempt to improve their spatial skills.

During the course, students work on being able to visualize and sketch objects represented three-dimensionally in a two-dimensional format and vice versa. These skills are essential when one is making the transition to solid modeling computer-aided-drafting software, such as Pro/ ENGINEER (Holliday-Darr \& Lobaugh, 2003). At the end of the semester, the students' spatial skills are posttested using the VIZ software.

Our goal was to see whether there was a relationship between the students' scores on basic spatial tasks and their performance in class (Holliday-Darr \& Blasko, 2004). As is shown in Figure 2, scores on the spatial tasks increased from pre- to posttest, suggesting that the engineering students' spatial skills were improving over the semester. For example, an analysis of 290 engineering students across 3 years showed a significant improvement in MRT accuracy from the beginning to the end of the semester $[F(1,286)=14.05, p<.0001]$.

A series of stepwise multiple regressions examined the predictive value of the three spatial tasks on students' course grades and cumulative GPAs. An important question was whether scores on the spatial tasks would be predictive of course grades and GPA over and above the usual predictors of college success: verbal and math SAT scores and high school GPA. The best predictor of course grades were scores on the MRT and paper-folding tasks, which explained $20 \%$ of the total variance $[F(2,67)=$ $9.25, p=.0001]$. Adding math SAT scores increased the adjusted $R^{2}$ slightly to .231 . The best predictor of cumulative GPA was math SAT and MRT scores $(R=.42)$, explaining a small but significant $15 \%$ of the total variance $[F(2,70)=7.29, p<.001]$. Interestingly, each year that the VIZ site has been used to assess incoming 1styear students for supplemental course instruction, the failure rate for the course has decreased, from $33 \%$ in 2001 , to $20 \%$ in 2002 , and to $10.5 \%$ in 2003 .

Offsite data collection. One benefit of a Web-based system such as VIZ is that it can be easily used in a variety of settings outside of the laboratory. For example, in one project, we studied the feasibility and effectiveness of spatial training at home, in comparison with training in the lab for college men and women (Turos, Enas, Johnson, \& Blasko, 2002). Women and men were randomly assigned to one of three groups: lab training, self-training, or control. All the groups completed a preand posttest, using the VIZ MRT. The lab group $(n=36)$ came to the lab once a week for 4 weeks and completed spatial tasks on the VIZ site. The self-training group $(n=$ 40) came to the lab for a pre- and posttest but, in the weeks in between, were asked to use the site on their own at home. The control group $(n=32)$ came to the lab for 4 weeks but simply surfed the Web. Figure 3 shows the results of the MRT accuracy pre- and posttraining for the two experimental groups: laboratory training groups and self-training group. First, compliance was high in all the groups, and both women and men showed similar improvements in overall spatial performance. Both experimental groups performed better than the controls. However, the women said that they enjoyed the computer-based tasks significantly less than did the men and reported feeling pressured in the mixed-sex lab groups. The women in the self-training group reported being more comfortable working on the tasks at home and tended to access the site more often than did the men.

\section{Ongoing Development}

Most of this work has been accomplished using interdisciplinary development teams of undergraduate students in engineering, psychology, communications, and man-

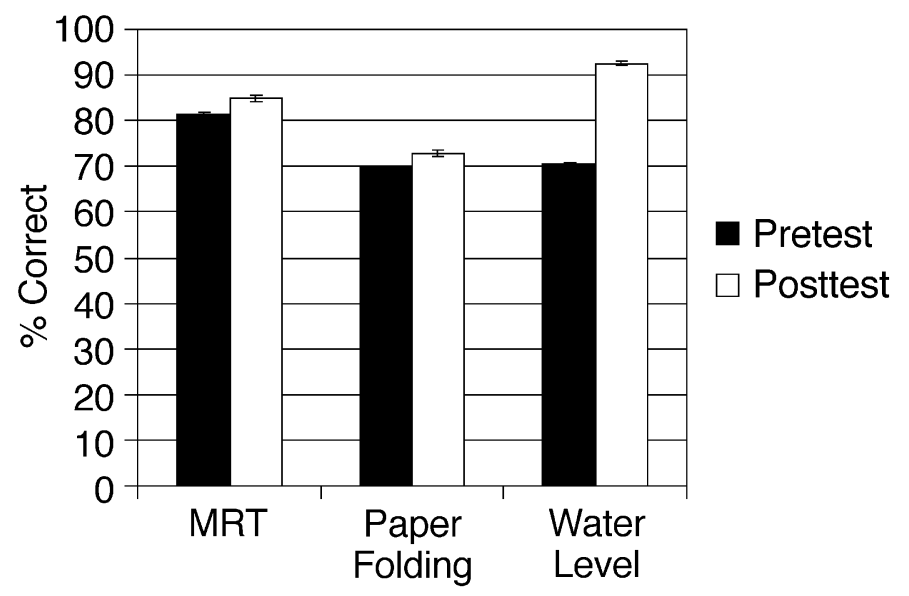

Figure 2. Mean percentage correct for the three spatial tasks of pretest (beginning of semester) and posttest (end of semester) for mechanical engineering technology and plastics engineering technology students. Error bars show standard error of the mean. 


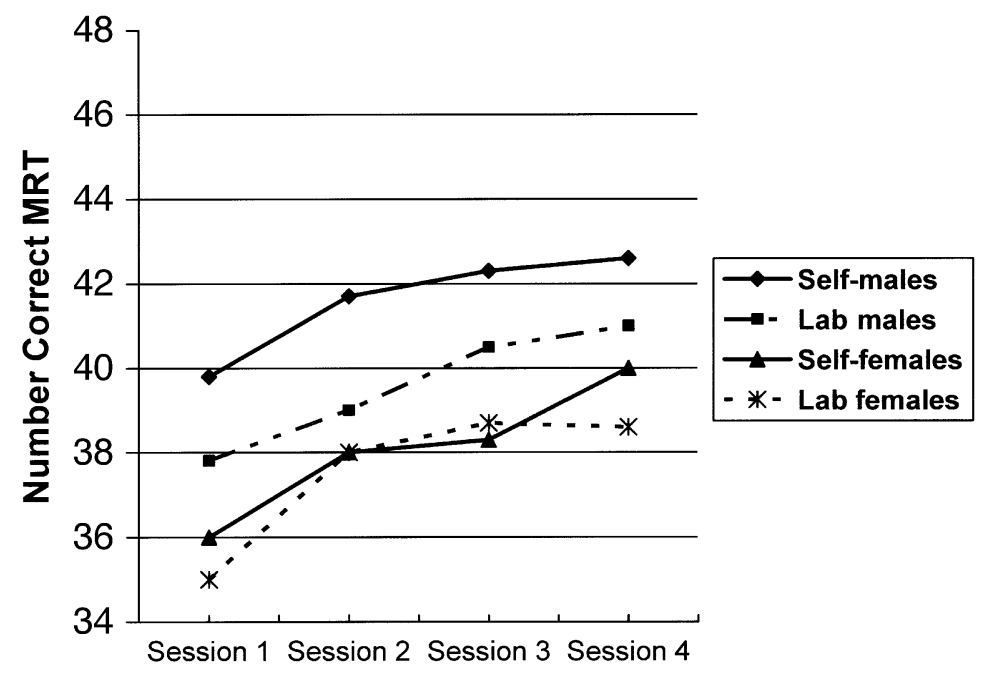

Figure 3. Mean number correct trials (out of 48) for men and women randomly assigned to self-training and lab-training groups across four administrations of the mental rotation task (MRT).

agement information systems. They have been working on a set of discipline-specific modules using Authorware to train fundamental concepts for engineering graphics, such as dimensioning. Two new modules are under development for the VIZ site. The first is a virtual version of the viewer/object rotation task developed by Wraga et al. (2000). The logic underlying the task is similar to the MRT; however, the lack of gender differences suggest that it may be possible to train or transfer aspects of the viewer task in order to develop strategies that improve female performance. The second task under development is a virtual wayfinding task consisting of guided or nonguided navigation through a novel environment with exposure to multiple cues or landmarks. This will provide an ecologically valid example of the integration of multiple spatial skill domains.

The site is currently being enhanced by the development of a set of Excel macros that will allow users to download their own data. They will create easy-to-use summaries, as well as allow access to individual subjects' data. This will make the site useful for researchers and to instructors in a variety of courses. The latest version of Authorware 7.0 also supports Macintosh users, and we are currently upgrading all of the VIZ modules.

\section{Conclusion and Availability}

The benefits of sites like VIZ are many. Web-based data collection allows those without laboratory facilities to collect high-quality data for classroom or research use. Large sets of data can be compiled very quickly, and data can be compared across ages and cultures and with varied ethnic groups. Instructors of engineering at other universities have been able to use the site to assess students' spatial skills and then offer supplementary instruction.

An important goal of the VIZ program is to offer an Internet-based tool that is available for instructors and re- searchers for the coordination, collection, and dissemination of data on a variety of spatial tasks. We feel we have fulfilled many of our original goals and have demonstrated that the on-line tasks are appropriate analogues to the traditional paper-and-pencil tasks. Our data appear to match specific trends seen in the literature on spatial skills testing. The portability of the VIZ modules should simplify the efforts of researchers to administer these tests and collect spatial data in atypical settings (e.g., classrooms, homes, or public settings). The extent of potential applications represents some exciting possibilities for collaborative research. We now extend the invitation to others to use the VIZ portal for evaluation, teaching, and research. Those with Authorware skills may contact the authors if they would like to contribute additional modules to the site.

\section{REFERENCES}

Bennett, G. K., Seashore, H. G., \& Wesman, A. G. (1973). Differential aptitude tests: Forms $S$ and T. New York: Psychological Corporation. Blasko, D., \& Holliday-Darr, K. (1999). Engineering and psychology: Joint project on visualization and engineering. Paper presented at the meeting of the American Society for Engineering Educators North Central Section, Erie, PA.

Devlin, A. (2001). Mind and maze: Spatial cognition and environmental behavior. Westport, CT: Praeger.

Holliday-Darr, K., \& Blasko, D. G. (2004). Relationship between spatial skills and class performance in introductory graphics engineering classes. Manuscript in preparation.

Holliday-DARR, K., Blasko, D., \& DWYer C. (2000). Improving cognitive visualization with a Web-based interactive assessment and training program. Engineering Graphics Design Journal, 64, 4-9.

HollidaY-DaRR, K. \& Lobaugh, M. (2003). Graphic claymation: Visualization through sight and touch. Proceedings of the American Society for Engineering Education. Available at http://www.asee.org/ conferences/caps/document/2003-2007_Final.pdf/.

Kimura, D. (1999). Sex and cognition. Cambridge, MA: MIT Press.

McGraw, K. O., Tew, M. D., \& Williams, J. E. (2000). The integrity of Web-delivered experiments: Can you trust the data? Psychological Science, 11, 502-506. 
Piaget J., \& Inhelder, B. (1956). The child's conception of space. London: Routledge \& Kegan Paul.

ShaH, P., \& MiYaKe, A. (1996). The separability of working memory resources for spatial thinking and language processing: An individual differences approach. Journal of Experimental Psychology: General, 125, 4-27.

Shepard, R. N., \& Metzler, J. (1971). Mental rotation of threedimensional objects. Science, 171, 701-703.

Turos, J., Enas, J., Johnson, A., \& Blasko D. G. (2002, January). Integrating teaching and research: Training spatial skills on the Web. Paper presented at the Engineering Design Graphics Division: Amer- ican Society for Engineering Education 56th Midyear Conference, San Francisco.

Voyer, D., Voyer, S., \& Bryden, M. (1995). Magnitude of sex differences in spatial abilities: A meta-analysis and consideration of critical variables. Psychological Bulletin, 117, 250-270.

Wraga, M., Creem, S. H., \& Proffitt, D. R. (2000). Updating displays after imagined object and viewer rotations. Journal of Experimental Psychology: Learning, Memory, \& Cognition, 26, 151-168.

(Manuscript received November 16, 2003; revision accepted for publication April 8, 2004.) 